\title{
Amoebic Liver Abscess
}

\author{
Dr. M M Rehman ${ }^{1}$, Dr. K.A.S.S.N.Kalyan², Dr.B.Anil Kumar ${ }^{3}$, \\ ${ }^{1}$ M. M Rehman M.S., General Surgery, Associate Professor, Dr.Pinnamaneni Siddhartha Institute of Medical \\ Sciences \& Research Foundation, Chinaoutapalli, Krishna Dist, Andhra Pradesh, India. \\ ${ }^{2}$ K. A.S.S.N.Kalyan, Junior Resident, General Surgery, Dr.Pinnamaneni Siddhartha Institute of Medical \\ Sciences \& Research Foundation, Chinaoutapalli, Krishna Dist, Andhra Pradesh, India. \\ ${ }^{3}$ Dr.B.Anil Kumar, M.S., General Surgery, Professor, Dr.Pinnamaneni Siddhartha Institute of Medical Sciences \\ \& Research Foundation, Chinaoutapalli, Krishna Dist, Andhra Pradesh, India.
}

\begin{abstract}
:
Background: Amoebic liver abscess presents with severe pain and high grade fever and if not diagnosed and treated promptly, may lead to complications and mortality.

Aim and objectives: The objective of the present study was to estimate the incidence, need for aspiration and prognosis. The diagnosis was based on clinical features, ultrasonography, aspiration of anchovy sauce from the liver lesion.

Results: 50 patients included in the study all of them being male. Different management options tried based on size ranging from antibiotic theraphy to aspiration and pigtail placement

Conclusion: Clinical background and sonogram give a reasonable suggestion about amoebic etiology.

Aspiration or pigtail catheterisation are commonly indicated based on size and other factors.

Conservative treatment with oral or intravenous metronidazole is successful for small sized abscess.

Keywords: Amoebic liver abscess; E.histolytica; metronidazole; percutaneous aspiration
\end{abstract}

\section{Introduction}

Amoebic liver abscess is also known as tropical liver abscess, dysenteric abscess or metastatic abscess of intestinal amoebiasis. It is more appropriately called amoebic liver necrosis as it is a necrosis of liver cells caused by Entamoeba histolytica. It is not an abscess in the true sense of the term as the so called 'pus ' does not contain pus cells and is bacteriologically sterile. It has evoked considerable concern in surgical and medical practice owing to it's increased frequency, chronicity and complications with which the patient presents. It is very commonly seen in tropical country like India owing to poverty, poor hygiene and lack of sanitation. The emphasis is on early diagnosis and treatment to prevent complications. With the advent of imaging modalities like ultrasonography, CT scan and serological tests like IHA, diagnosis and management has become easier with resultant decrease in mortality and morbidity.

\section{Aim and objectives}

The objective of the present study was to estimate the incidence, need for aspiration and prognosis. The diagnosis was based on clinical features, ultrasonography, aspiration of anchovy sauce from the liver lesion.

\section{Materials and methods}

A series of 50 cases of amoebic liver abscess admitted to our hospital, Dr.PSIMS and RF, chinnoutpalli between September 2013 and September 2015 were studied.

In each case an accurate diagnosis was made on history, clinical examination and investigations including liver function tests and ultrasonography. ELISA was carried out in all patients. The patients were treated depending upon the clinical presentations and size of the abscess as seen on ultrasonography.

Aspiration was done using $16 \mathrm{G}$ Lumbar puncture needle or $16 \mathrm{~F}$ i.v. Cannula and a syringe. $2-3 \mathrm{ml}$ of $2 \%$ Lignocaine was used for local anaesthesia. Ultrasound was done at the end of the procedure to see complete evacuation of abscess. If residual abscess was found, the position and depth of needle was changed or even the puncture site was changed till there was complete evacuation. The numbers of aspirations as well as the number of punctures to evacuate the abscess were noted. 


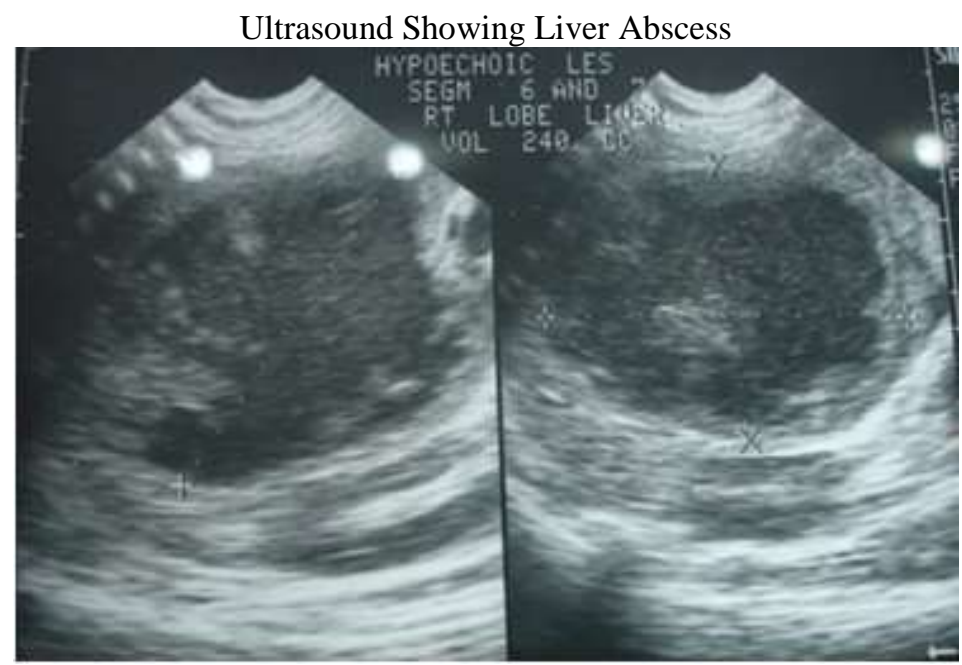

A) Patients with abscess size less than $5 \mathrm{~cm}$ were given anti amoebic chemotheraphy only. Anti amoebic chemotheraphy consisted of Metronidazole (800mg) 8 hourly for 10 days and Chloroquine $1 \mathrm{gm} /$ day for 2 days followed by $500 \mathrm{mg} /$ day for 19 days.

B) Surgical intervention in the form of ultrasonography-guided aspiration was done for patients with

1) abscess size more than $5 \mathrm{cms}$

2) patients with impending rupture

3) left lobe abscess and

4) patients with multiple abscesses.

C) Pigtail catheter drainage was done for abscesses which filled up despite repeated aspiration (2-3 times) ruptured abscess with extrahepatic contamination.8-10 Fr pigtail catheter was inserted under ultrasonography guidance.

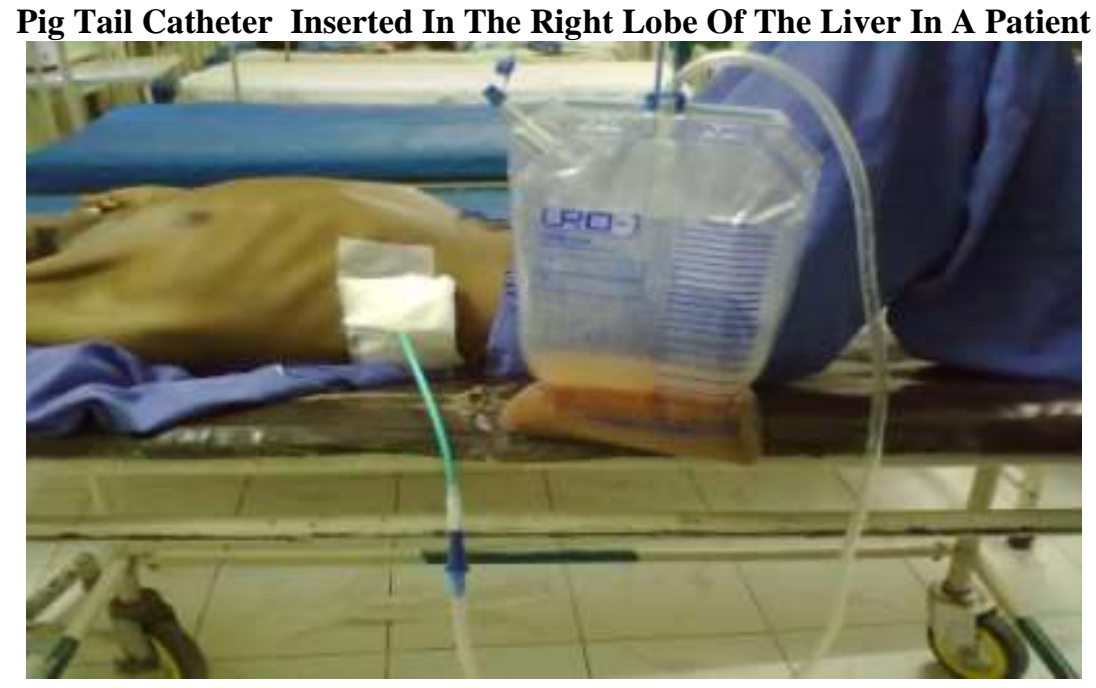

D) Exploratory laparotomy was done for abscess, which had ruptured intra Peritonially causing peritonitis. Abdomen was opened by midline incision, pus was sucked out following which warm saline wash was given. Abdomen was closed after keeping two drains in the abdominal cavity one in the pelvis and another drain at the site of the abscess cavity. Patients were given broadspectrum antibiotics in addition to anti amoebic chemotherapy, intravenous fluids and blood transfusions as and when necessary.

E) Drains under local anesthesia were inserted for patients who were not fit for surgery.

The patients were examined daily for clinical improvement. Improvement in pain, fever, anorexia and hepatomegaly were considered criteria for successful treatment. Mean hospital stay was recorded in each group. Ultrasound was repeated twice a week to look for resolution of the liver abscess. 


\section{Results and Discussion}

In our study,72 \% of the patients were between $21-50$ years of age. The Youngest being 21years and oldest 72 years of age. Katzenstein et al5 (1)in a study of 69 patients observed that amoebic liver abscess occurred predominantly in patients in the age group 16- 60 years. In our study there was a preponderance among the male population $(100 \%)$. Rollestan (2) suggested that the increased incidence in males is probably due to increase alcohol intake predisposing to hepatic congestion. Alcohol is commonly believed to play some role in the etiology of amoebic liver abscess and many patients give a past history of consuming it. In our study $64 \%$ of the cases gave history of alcoholism. Subramanium ,R.Krishnan (16) in their study had $62.5 \%$ of the patients giving history of alcoholism.

Dysentry with passage of blood and mucus in the stool was encountered in only $12 \%$ of our cases. Barnes and Lillemoe (5) in their study had $35 \%$ of the patients with history of blood and mucus in stool. According to Shyam Mathur(15) diarrhoea was seen in $7 \%$ of patients.

The commonest symptom noted in our series was abdominal pain (100\%) followed by fever $(90 \%)$, and Jaundice (12\%). Pain was most commonly felt in the right hypochondrium and constituted a dullache or a sharp stabbing pain.Liver tissue itself is insensitive to pain and its presence indicates stretching of the liver capsule or rupture of the abscess. Wilmot (3) reported in his series an incidence of $99 \%$ for abdominal pain.

The second commonest symptom in our study was fever (90\%).Debakey and Ochsner (4) reported incidence of fever in $87 \%$ of cases while Wilmot (3) has reported fever in $81 \%$ of the cases. Shyam mathur et al (13) observed that fever occurred in $87 \%$ of patients .

Jaundice with clinically observed icterus was noted in $30 \%$ of the cases, bilirubin more than $1.2 \mathrm{mg} / \mathrm{dl}$ was found in $44 \%$ of the cases. This finding is similar to those of Turrill et al (7) (32\%). The causes of jaundice in amebic liver abscess may be (a) massive destruction of hepatocytes (b) associated inflammatory changes of adjoining areas and (c) mechanical obstruction of the biliary canaliculi by the expanding abscess.

Local tenderness confined to the right hypochondrium was the commonest elicited clinical sign in 100 $\%$ of our cases where as Ramachandra et al (6) reported $90 \%$ of the patients with local tenderness in the right hypochondrium. Hepatomegaly resulting from coalescence of multiple hepatic microabscesses leading to expanding interhepatic space occupying lesion was seen in $72 \%$ of our cases, where as findings of Madangopalan (7) reported $86 \%$ of patients having hepatomegaly in his clinical study.

The important hematological and biochemical investigations carried out in our study-included haemoglobin, leukocyte count and liver function tests.Haemoglobin less than $10 \mathrm{gm} \%$ was found in $22 \%$ of our patients. While blood cells count more than 11,000 cells/cu.mm was seen in 72\% of the patients.Qin SL, Wang AX (9) in their study have reported leucocytosis in $61 \%$ of their patients.

Raised Alkaline phosphotase was seen in $58 \%$ of the cases in our study and raised bilirubin more than $1.2 \mathrm{gm} \%$ was found in $44 \%$ of the cases in our study.X-ray chest was done in all the cases. In $26 \%$ of the patients the dome of the diaphragm was raised on right side and $26 \%$ of the patients showed associated pleural effusion.

The most important imaging modality in present day scenario for diagnosis and management of amoebic liver abscess is ultrasonography as (a) it may detect lesion greater than $1 \mathrm{~cm}$. (b) it determines exact number and location of the abscesses (c) it is cheaper and has no radiation hazards (d) it can be repeated and (e) therapeutic aspiration and pigtailing can be done.Ultrasonography was done in all our cases,in $86 \%$ of the cases the abscess was in the right lobe of the liver, in $10 \%$ of the cases the abscess was in the left lobe of the liver and $40 \%$ of the cases has multiple abscesses. According to Chaturbhuj Lal Rajak, Sanjay Gupta(14) solitary abscesses were seen in $72 \%$ of cases and multiple abscesses were seen in $18 \%$. Abscess were located in the right lobe in $72 \%$ of cases and left lobe in $12 \%$ of cases. Both lobe involvement was seen in $20 \%$ of their cases.

Ct Scan Showing Large Right Lobe Abscess

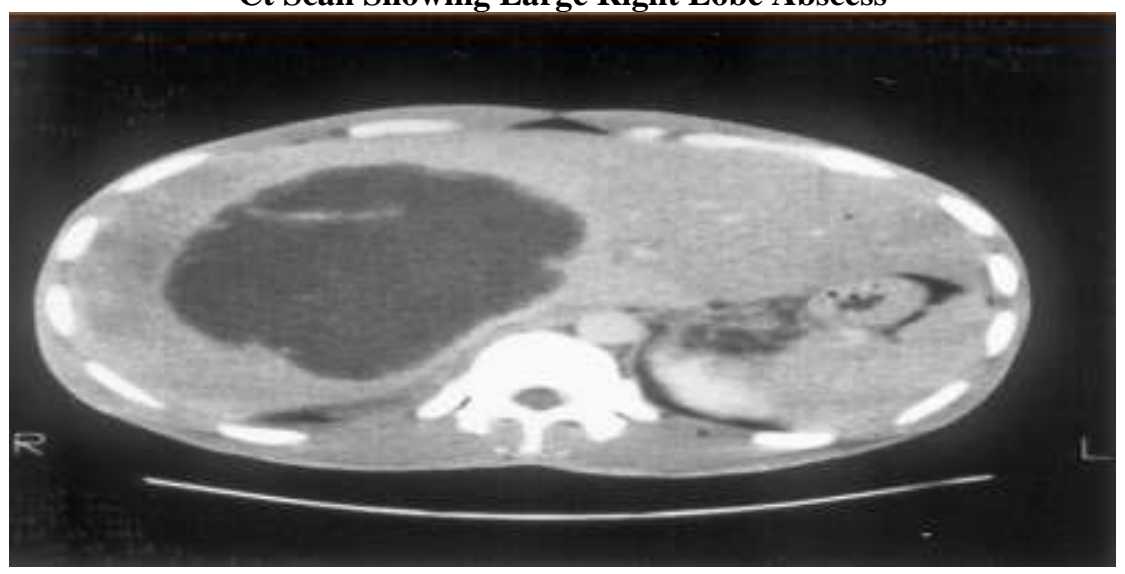


C.T scan was done in 7 cases in our study for patients with amebic liver abscess. C.T scan is more sensitive than ultrasonography, it shows anatomical and morophological defect in the liver and helps in exact localization of the abscess and also tells about the depth of the abscess. ELISA for amoebiasis was done and all these cases showed positive result. HIV was done in all the patients, and were seronegative .

The management given in our series of 50 patients includes

1) Only anti amoebic chemotherapy in $19 \%$ of the patients.

2) Majority of the patients $(56 \%)$ were treated by ultrasonography guided aspiration and antiamoebic chemotherapy for abscess size between $5 \mathrm{~cm}$ to $10 \mathrm{cms}$ as seen on USG.

3) Pigtailing was done in $24 \%$ of the cases for abscess size more than $10 \mathrm{~cm}$ and complicated ruptured amoebic liver abscess with extraheptic contamination excluding periotonitis.

4) Exploratory laparotomy was done in $2 \%$ of the patients for ruptured liver abscess with periotonitis and

5) Drains under local anaesthesia were inserted for patients not fit for anaesthesia.

Studies carried out by Arshad Zaffar and Sajjad Ahmad (10) has concluded that needle aspiration combined with anti amoebic chemotherapy is more effective than drug treatment alone in the management of amoebic liver abscess.Qin SL Wang AX (9) in their study has said that medical therapy alone was excellent for small abscesses while percutaneous needle aspiration or draining was a successful approach in patients with large abscesses. Baijal SS, Agarwal DK, Roy S (17) have found that patients with ruptured amoebic liver abscess can be effectively and safely managed by percutaneous catheter drainage irrespective of the extent of extrahepatic contamination.

In our study of 50 cases of amoebic liver abscess complications encountered are in 3 cases (5\%) with hepatobronchial fistula, 4 cases $(6.6 \%)$ with sub diaphragmatic rupture of amoebic liver abscess and 2 cases (4\%) with rupture into the peritoneal cavity causing peritonitis. CT scan established the diagnosis in these complicated cases except for one case in which exploratory laparotomy was directly done for peritonitis and was found to have ruptured amoebic liver abscess.Patients with hepatobronchial fistula were treated by pigtail insertion in the abscess cavity and chest physiotherapy along with antiamoebic chemotherapy. 4 cases of sub diaphragmatic rupture of amoebic liver abscess were also treated by pigtail insertion into the sub diaphragmatic collection.

Patients with ruptured liver abscess into the peritoneum with peritonitis were treated by exploratory laparotomy with drainage of pus and antiamoebic chemotherapy.Meng Xy. Wu JX (12) in their study of 503 consecutive cases of amoebic liver abscess documented 110 cases (22\%) complicated by rupture of the abscess. Ruptured sites include pleuropulmonary in 79 cases (72\%) subphrenic space in 15 cases (14\%) and peritoneal cavity in 11 cases $(10 \%)$.

All the 50 cases in our study responded to the treatment given to them and were discharged. The average hospitalization time in patients with abscess size less than $5 \mathrm{cms}$ was 10.7 days, patients with abscess size 5-10 cms was 13.7 days and or patients with abscess size more than $10 \mathrm{cms}$ was 13.5 days. Schweizer W, Burthold M. (13) in their study reported the mean hospitalization time of 16.5 days for patients with liver abscess

\section{Conclusion}

Amoebic liver abscess is the commonest extra intestinal complication of intestinal amoebiasis and occurs fairly frequently in Indian population.High index of suspision is mandatory for early clinical diagnosis. with the advent of newer imaging modalities like USG , CT scan diagnosis has become easier. Serological tests like IHA are very useful in diagnosis of amoebic liver abscess. It has a high sensitivity of 95-100\%. Early diagnosis and treatment has lead to a reduction in morbitidy and mortality.

Preventive measures at individual level and community level can help in eliminating the disease. 1) personal measures are a) Use of boiled drinking water. b) protection of all food and drinks from contamination by flies, cockroaches and rats. c) Avoid use of raw vegetables and fruits. d) Personal cleanliness and elementary hygienic condition are to be observed while taking meals. 2) Community measures are a) Effective sanitary disposal of feaces. b) protection of water supplies from fecal contamination. c) Avoid use of human excrement as fertilizer. d) Detection, isolation and treatment of carriers.Prophylaxis in the form galactose and $\mathrm{N}$-acetyl galactosamine inhibitale lectin, a surface antigen of E.Histolytica as vaccine for amoebiasis is not far away. 


\section{References}

[1]. Katzenstein D, Rickerson V, Braude Abraham : New concepts of amoebic liver abscess derived from hepatic imaging, serodiagnosis, and hepatic enzymes in 67 consecutive cases in San Diego. Medicine 1982; 61:237-46.

[2]. Rollestan and McNee, diseases of liver, gall bladder and bile ducts.1929 Sharma MP, Ahuja Vineet. Amoebic liver abscess : Clinician's perspective. Bombay Hospital Journal 1997; 39: 615-9.

[3]. Wilmot, A J. Clinical Amoebiasis,Blackwell Scientific Publications.Oxford 1962

[4]. Debakey ME, Oschner A. Hepatic Amoebiasis : A 20 years experience and analysis of 263 cases. Surgery, Gynaecology and Obstetrics 1951; 92: 209- 231.

[5]. Stephen Barnes and Keith Lillemoe, Magingot's Abdominal Operation. 10 ${ }^{\text {th }}$ edition, 1997:2:1561

[6]. Ramachandran S, Sivalingam S, Perumal JR ; Concepts in hepatic amoebiasis. J Trop Med Hyg. 1973 Feb;76(2):39-42 .

[7]. Subramanian R, Madangopalan N, 1970. Amoebiasis Monography Bombay, India: Sandoz India.

[8]. Turrill FL, Burnham JR. Hepatic amebiasis. Am J Surg. 1966 Mar;111(3):424- 430.

[9]. Qin SL,Wang L,Sheng RY,Liuzt.[Clinical analysis of 36 cases with amoebic liver abscess.] Zhongguo Ji Sheng Chong Xue Yu Ji Sheng Chong Bing Za Zhi. 2000;18(6):356-8

[10]. Arshad Zafar and Sajjad Ahmed, Amoebic liver abscess: A comparative study of needle aspiration versus conservative management. J Ayub Med Coll Abbottabad 2002; 14(1) pp 10-12.

[11]. Baijal SS, Agarwal DK, Roy S ; Complex ruptured amoebic liver abscess: The role of percutaneous catheter drainage. Eur J Radiol. 1995 May;20(1):65-7.

[12]. Meng XY,Wu, JX ; Perforated amoebic liver abscess:Clinical analysis of 110 cases. South Med J.1994 Oct;87(10):985-90.

[13]. Schweizer W, Berthold M, Naef M, \{clinical aspects, etiology diagnosis and therapy of liver abscess. A retrospective study 1984$1991\}$ Schweiz Med Wochenschr. 1994 Sep 17;124(37): 1633-9.

[14]. Chaturbhujlal Rajak, Sanjay Gupta, Yogesh Chowla. Percutaneous treatment of liver abscess. American Journal of Roentgenology 1998; 170: 1035-1039.

[15]. Shyam Mathur, RS Gehlot, Alok Mohta, Narendra Bhargav;Clinical Profile of Amoebic Liver Abscess; JIACM 2002; 3(4): 36773.

[16]. Subramaniam R. Krishnan K.T et al, J. Ass Phys Ind. 1970; 18: 729

[17]. Viroj Wiwanitkit, Liver abscess , MD, Medscape General Medicine 4(3), 2002. 